\title{
Influence of the shape and mass of a small robot when thrown to a dummy human head
}

\author{
Ahmad Yaser Alhaddad $^{1,2} \cdot$ John-John Cabibihan ${ }^{1}\left[\right.$ [ $\cdot$ Ahmad Hayek $^{1} \cdot$ Andrea Bonarini $^{2}$
}

Received: 1 June 2019 / Accepted: 3 October 2019 / Published online: 24 October 2019

(C) The Author(s) 2019 OPEN

\begin{abstract}
Social robots have shown some efficacy in assisting children with autism and are now being considered as assistive tools for therapy. The physical proximity of a small companion social robot could become a source of harm to children with autism during aggressive physical interactions. A child exhibiting challenging behaviors could throw a small robot that could harm another child's head upon impact. In this paper, we investigate the effects of the mass and shape of objects thrown on impact at different velocities on the linear acceleration of a developed dummy head. This dummy head could be the head of another child or a caregiver in the room. A total of 27 main experiments were conducted based on Taguchi's orthogonal array design. The data were then analyzed using ANOVA and then optimized based on the signalto-noise ratio. Our results revealed that the two design factors considered (i.e. mass and shape) and the noise factor (i.e. impact velocities) affected the response. Finally, confirmation runs at the optimal identified shape and mass (i.e. mass of $0.3 \mathrm{~kg}$ and shape of either cube or wedge) showed an overall reduction in the resultant peak linear acceleration of the dummy head as compared to the other conditions. These results have implications on the design and manufacturing of small social robots whereby minimizing the mass of the robots can aid in mitigating the potential harm to the head due to impacts.
\end{abstract}

Keywords DOE $\cdot$ Taguchi $\cdot$ Signal to noise ratio $\cdot$ Robot design $\cdot$ Safety $\cdot$ Autism

\section{Introduction}

The global interest in robots is on the rise due to various advances in artificial intelligence and sensing technologies that made them more autonomous and intelligent (Fig. 1) $[17,42]$. This opens up new possibilities in the application of robots in new areas [1]. These developments have implications and raise some safety concerns [2].

The interest in social robots and their clinical applications in assisting the therapy of children with Autism Spectrum Disorder (ASD) has grown considerably due to the reported evidences of their efficacy $[15,21]$. Unlike their neurotypical peers, children with ASD exhibit stereotypical and challenging behaviors. The reported prevalence rates of challenging behaviors among individuals with autism are high. Previous studies reported occurrence rates of greater than $49 \%$ and up to $69 \%[10,11,31]$.

Unlike typical toys, social robots have the ability to demonstrate emotions, establish social connections, display of personalities, use cues, and engage with partners at an interpersonal level $[18,43,49]$. The introduction of robots to children with ASD represents new challenge that must be taken into account. For example, children interacting with social robots might show some aggression $[8,14,25]$. Furthermore, robots are meant to elicit behaviors $[19,21]$. Hence, the introduction of such technology to children with ASD could represent a potential harm during the manifestation of unwanted

John-John Cabibihan, john.cabibihan@qu.edu.qa| 'Department of Mechanical and Industrial Engineering, Qatar University, 2713 Doha, Qatar. ${ }^{2}$ Department of Electronics, Information and Bioengineering, Politecnico di Milano, Piazza Leonardo da Vinci 32, 20133 Milan, Italy. 
Fig. 1 Some of the commercially available robotic toys with small form factor. a Cozmo, a real-life tiny robot (With kind permission from Anki). b Alpha 1 Pro, a humanoid robot companion (With kind permission from UBTECH). c ELMOJl, a fun teaching robot (With kind permission from WowWee Group Ltd). d Ollie, an app-controlled robot (With kind permission from Sphero). e Droid, a programmable robot (With kind permission from Littlebits). f Codey Rocky, a programming teaching robot (With kind permission from Makeblock)

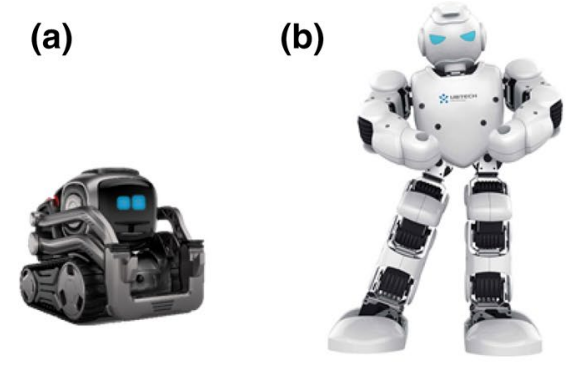

(c)

(d)
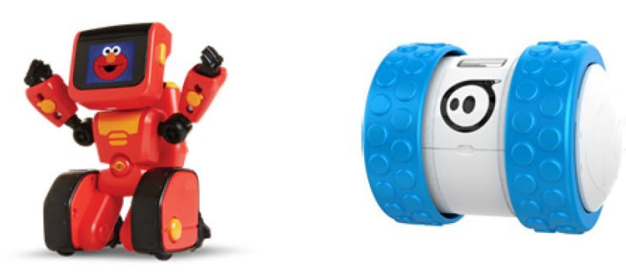

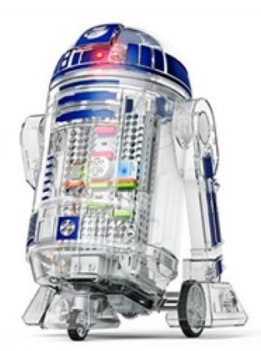

(f)

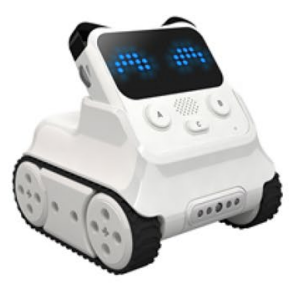

behaviors (e.g. kicking, throwing, and banging [32]). For instance, a thrown small robot that hits the head might cause subconcussion or superficial injuries [2]. There is a need to evaluate social robots to achieve safe physical human-robot interaction during such scenarios.

When the head is subjected to bumps or blows and impacts with objects, a traumatic brain injury (TBI) might occur. In serious cases, TBI could lead to a disability or, in extreme cases, it could cause death. The occurrence of TBI among children was reported to cause challenges, such as disabilities and impairment in daily skills [9, 39]. In 2013 alone, 2.8 million cases of TBI have been reported in the United States [47]. The cases of TBI among children were occurred due to getting struck by or against an object. A study analyzing mild brain injuries among children in Sweden for the years 1998 and 1999 has found that 47\% of the cases occurred at home and during playtime or leisure activity and due to childcare products, which includes toys [23]. These figures have many implications on the design of robotic toys pertaining to the safety of the head. There is a need for further safety considerations and userfocused design to take into account the characteristics of special needs users, such as children with ASD $[2,8]$. The work in social robots safety is still limited $[22,28]$, especially in relation to improving design aspects of small robots $[13,16,29,48]$.

In this paper, we investigate two design factors (i.e. mass and shape) of a small robot that is subjected to different throwing velocities (i.e. noise factor) and understand their effects on the acceleration of a dummy's head. Furthermore, we identify the conditions of the design factors at which the response is minimized. This paper is structured as follows. Section 2 presents the design of experiment. Section 3 describes the materials and methods while Sect. 4 provides the results. Section 5 describes the discussion. Finally, Sect. 6 provides the conclusion.

\section{Design of experiment}

\subsection{Taguchi design}

Experiments are usually conducted on processes and systems to understand the overall performance, to deduce the most influential parameters, and to determine the optimal settings to achieve the desired responses or overall goals [35]. Design of experiment (DOE) is an approach aimed at using the minimum amount of resources available while maximizing the amount of information obtained from a process through the selection of parameters to be investigated [35]. DOE helps in collecting different information by altering the optimal arrangement of parameters or factors to enhance product robustness $[20,26]$. There are many DOE techniques available. The choice depends on the investigated problem and the aim of the experiments conducted [20]. One of such techniques is the Taguchi method.

The method was developed in 1979 and was meant to be used as an off-line quality control tool to improve manufacturing products and goods [45]. Furthermore, it has been considered in different applications [7, 27, $34,46]$. Taguchi DOE considers two types of variables, namely controllable and noise (or uncontrollable). Control factors can be controlled in production while noise 
factors cannot be controlled, except experimentally. This method aims to improve the robustness of products against any variations in the noise factors by finding the optimal values of the controllable factors. Depending on the number of factors investigated, Taguchi DOE could take on different settings by considering different orthogonal arrays (OAs) [36]. The crossed array Taguchi design that was considered in this study provides robust solution by understanding the interaction between the control factors and the noise factors [20].

\subsection{Experimental factors}

The goal is to investigate whether the shape or the mass plays any role in affecting the response. Hence, two control factors are considered in this investigation for their possible influence in attenuating the peak acceleration of the head. Twenty seven (i.e. $9 \times 3$ ) experiments must be conducted to cover all the possible combination of all the factors based on the $L_{9}\left(3^{2}\right)$ OA (Table 1). The considered control and noise factors are independent.

The levels of all the factors have been defined (Table 2). The range for the mass is comparable to that of small robotic toys. For the sake of simplicity, the selection of the overall shapes of the form factor were limited to three basic 3D geometric shapes while ignoring any other features. For consistency, the noise levels were limited to low velocities divided into three levels (i.e. < $3 \mathrm{~m} / \mathrm{s}$ ) [37].

Table 1 The standard $L_{9}\left(3^{2}\right)$ orthogonal array (OA)

Table 2 The experimental factors and their descriptions. The impact velocity levels are represented by the mean and the standard deviation

\section{Materials and methods}

\subsection{Impact setup}

The impact setup that was used to conduct the experiments contained a 3D-printed head that was mounted on a frame (Fig. 2). The mass of the dummy head was made close to that of children's dummy heads [44]. To measure the linear acceleration of the head, an accelerometer was placed inside the head. The data was acquired at $20 \mathrm{kHz}$. The impact setup has been shown to give similar results to that of related studies. More indepth details about the experimental setup and validation can be found in our earlier studies $[2,4,6,7]$.

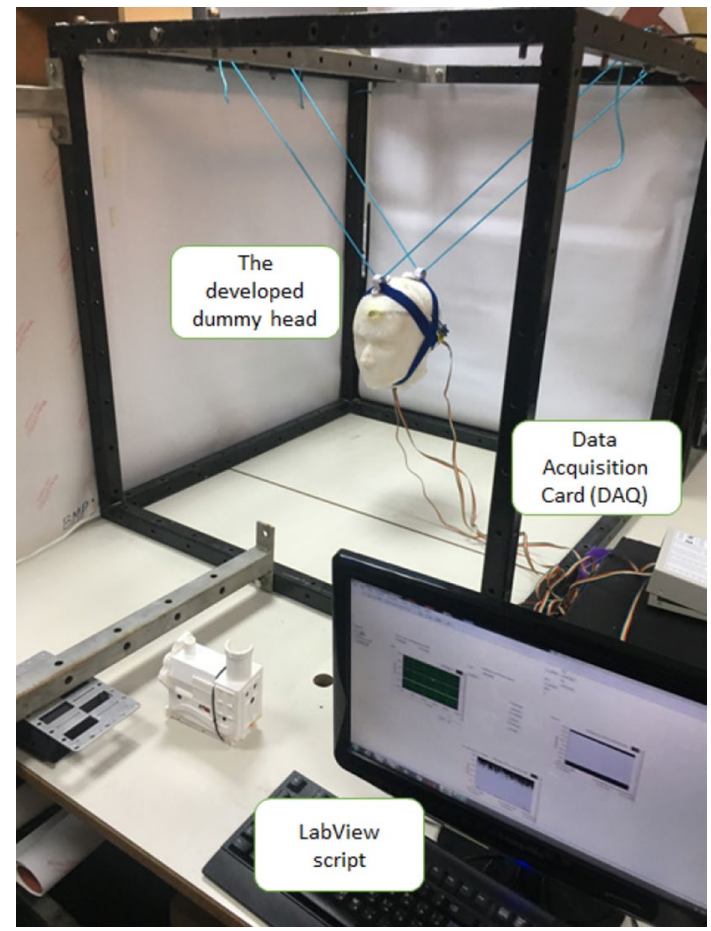

Fig. 2 The impact setup that was used to conduct the experiments showing the developed dummy head, data acquisition card, and the computer system that was used to acquire and store the data [2]

\begin{tabular}{llllll}
\hline Type & Factor & Code & Level 1 & Level 2 & Level 3 \\
\hline Control & Mass $(\mathrm{kg})$ & A & 0.3 & 0.4 & 0.5 \\
Control & Shape & B & Cube & Cylinder & Wedge \\
Noise & Impact velocities $(\mathrm{m} / \mathrm{s})$ & $\mathrm{X}$ & Low & Medium & High \\
& & & $(1.14 \pm 0.10)$ & $(1.72 \pm 0.12)$ & $(2.7 \pm 0.10)$ \\
Response variable & Peak linear head acceleration $(\mathrm{g})$ & & & & \\
\end{tabular}




\subsection{Impactors}

We want to understand the influence of the mass and shape of a small robot on the resultant peak linear head acceleration due to an impact. Hence, 3D models of three basic shapes were considered (Fig. 3). The shapes were constructed using a 3D printer (Replicator 5th Generation, MakerBot Industries, USA). A clay material was used to adjust the mass of each shape according to the mass levels in Table 2. The center of mass was made sure to be balanced for all the impactors.

\subsection{Procedures}

All experiments were performed according to the $L_{9}\left(3^{2}\right)$ orthogonal array (OA) (Table 1). For each noise level, 9 experiments were conducted that have covered all possible combinations of the control factors (See supplementary material and $[3,5])$. The objects were tied to the frame which provided a controlled condition in the execution of the experiments (Fig. 4). Furthermore, it has provided more consistent impact velocities by adjusting the drop height of an object. Three different drop locations generated three different noise levels. The impact velocities were based on the video analysis of the experiments (Table 2). As for the confirmation runs, 18 experiments were conducted.
The impact velocities were estimated based on the slow-motion recordings of the experiments using a video analysis software (Tracker v5.0.7 [12]). The raw acceleration readings were obtained using a data acquisition card that then stored using a LabView script. Finally, the peak head acceleration for each experiment was calculated based on a MATLAB script. More detailed procedures can be found in our earlier studies $[2,4,6,7]$.

\subsection{Head severity index}

Several head severity indices were used in the literature to study the potential harm to the head, such as Head Injury Criterion, $3 \mathrm{~ms}$ criterion, and peak head linear acceleration. Previous studies have considered the peak linear acceleration of the head to investigate concussive events due to impacts $[41,51]$. Among hockey players, an earlier study has reported the possibility of the occurrence of a concussion at $31.8 \mathrm{~g}$ [33]. Another study investigating football impacts identified the occurance of subconcussive events at $26 \pm 20 \mathrm{~g}$ [40]. Dummies that report the head acceleration were also considered to evaluate the potential injuries to the head (e.g. in industrial robots and in sports [24, 38, 50]). Similarly, the impact setup in this study will use the peak linear head acceleration only as an indicator to sudy the influence of the considered factors. (a)

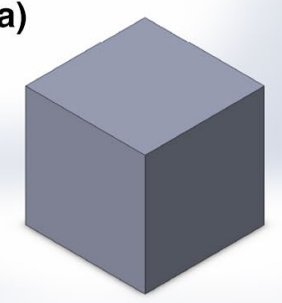

(b)

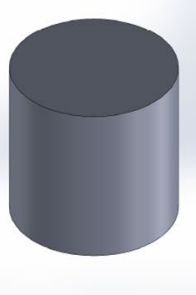

(c)

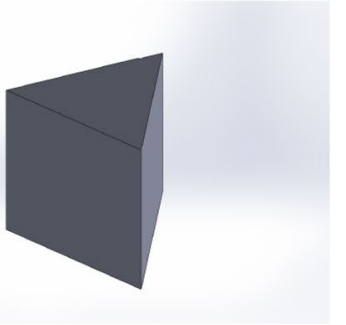

Fig. 3 The three basic 3D designs of the impactors that have been considered in the study. a Cube $\left(10 \times 10 \times 10 \mathrm{~cm}^{3}\right.$, length, width and height). b Cylinder $\left(10 \times 10 \mathrm{~cm}^{2}\right.$, diameter and height). c Wedge $\left(10 \times 10 \mathrm{~cm}^{2}\right.$, length and height). For simplicity, the three basic featureless shapes were considered to isolate the contribution of the shape on the response
Fig. 4 Samples of the experiments that were conducted in this study a For the cube. b For the cylinder. c For the wedge
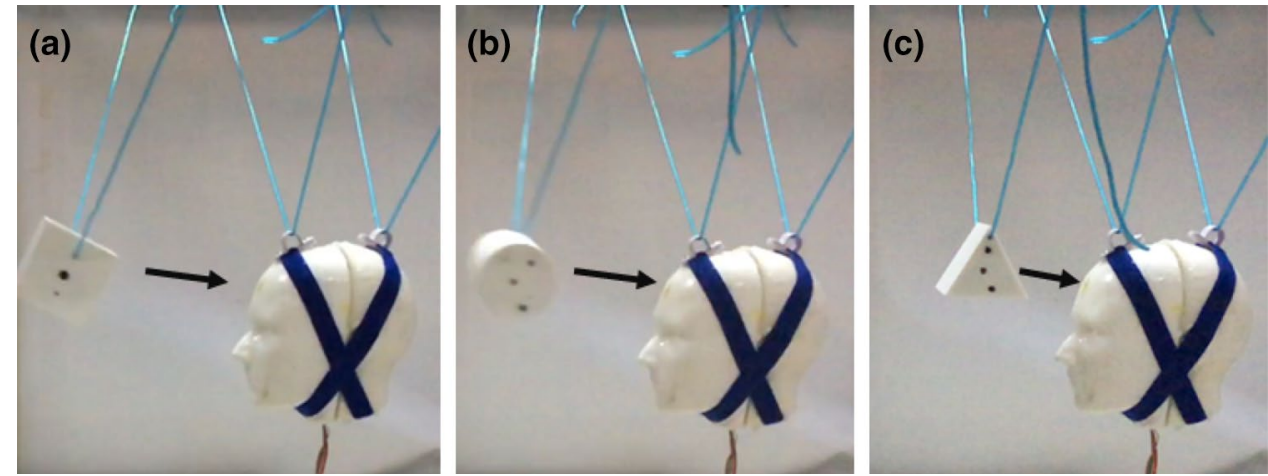


\subsection{Data analysis}

\subsubsection{ANOVA}

To study the significance of each factor on the head's acceleration, a three-way analysis of variance (ANOVA) test was conduced on the inverse of the average responses of all the investigated factors. The level for statistical significance was set to $p<0.05$. All analyses were performed using Minitab (v19.1, Minitab Inc., USA).

\subsubsection{Signal to noise ratio}

The optimization technique considered is the signalto-noise $(\mathrm{S} / \mathrm{N})$ ratio. The aim of this study is reduce the head's acceleration. Hence, the appropriate $\mathrm{S} / \mathrm{N}$ ratio was selected, and it is defined as[20]:

$S / N=-10 \log _{10} E\left[y_{i}^{2}\right]$

where $E$ is the expectation and $y_{i}^{2}$ is the head's acceleration (i.e. the response).

\section{Results}

\subsection{Orthogonal array}

The Taguchi $L_{9}$ orthogonal array was completed by finding the average response, the standard deviation, and the respective $\mathrm{S} / \mathrm{N}$ ratio for each combination of the investigated factors (Table 5). The range for the linear acceleration values was 2.72 to $13.03 \mathrm{~g}$. The lowest response value was at a mass of $0.3 \mathrm{~kg}$, wedge shape, and Level 1 impact velocity (i.e. A1-B3-X1). As for the highest response, it occurred at a mass of $0.5 \mathrm{~kg}$, cylinder shape, and at an impact velocity Level 3 (i.e. A3-B2-X3). The lowest overall average response across all factors was $3.95 \mathrm{~g}$ with a S/N ratio of -12.05 and was due to Level 1 velocity (Tables 3 and 4). On the other hand, Level 3 velocity scored the highest average response (ie. $9.70 \mathrm{~g}$ ) with a $\mathrm{S} / \mathrm{N}$ ratio of -19.91 .

Table 3 The average response at every level of each factor

\begin{tabular}{llll}
\hline Level & Mass & Shape & Impact velocity \\
& A & B & X \\
& Mean (SD) & Mean (SD) & Mean (SD) \\
\hline 1 & $5.73(0.75)$ & $6.86(1.49)$ & $3.95(0.67)$ \\
2 & $7.19(0.77)$ & $7.88(1.21)$ & $7.77(1.43)$ \\
3 & $8.51(0.41)$ & $6.69(1.49)$ & $9.70(2.07)$ \\
\hline
\end{tabular}

Table 4 The average signal-to-noise $(\mathrm{S} / \mathrm{N})$ ratios at every level of each factor

\begin{tabular}{llll}
\hline Level & Mass & Shape & Impact velocity \\
& $\mathrm{A}$ & $\mathrm{B}$ & $\mathrm{X}$ \\
& $\mathrm{S} / \mathrm{N}$ & $\mathrm{S} / \mathrm{N}$ & $\mathrm{S} / \mathrm{N}$ \\
\hline 1 & -15.55 & -16.90 & -12.05 \\
2 & -17.54 & -18.43 & -17.94 \\
3 & -19.10 & -16.85 & -19.91 \\
\hline
\end{tabular}

\subsection{ANOVA}

The statistical significance of each factor on the average response due to varying their levels was investigated based on a three-way ANOVA test. The inverse transformation of the response was considered in this test. A post-hoc pairwise Tukey test was also conducted.

\subsubsection{The object's mass}

To understand the contribution of the mass on the head's acceleration, a three-way ANOVA was conducted (Table 6). The test revealed a statistical significance due to altering the conditions of the mass on the response $(F(2,8)=46.97, p=0.00)$ at the $p<0.05$. A post-hoc Tukey test showed that Level 1 mass $(M=5.73, S D=0.75)$, Level 2 mass $(M=7.19, S D=0.77)$, and Level 3 mass $(M=8.51$, $\mathrm{SD}=0.41)$ were statistically different at $p<0.05$.

\subsubsection{The object's shape}

To investigate the effects of the shape on the response, a three-way ANOVA test was conducted (Table 6). There was a significant difference due to the alteration of the shape on the response $(\mathrm{F}(2,8)=7.03, p=0.02)$ at $p<0.05$. A post-hoc Tukey test showed that Level 2 shape $(M=7.88, S D=1.21)$ differed significantly from Level 3 shape $(M=6.69, S D=1.49)$.

\subsubsection{The object's impact velocity}

To understand the contribution of the impact velocity, a three-way ANOVA was performed (Table 6). A significant difference was reported due to altering the conditions of the impact velocity on the head acceleration $(\mathrm{F}(2,8)=289.24, p=0.00)$ at $p<0.05$. A post-hoc Tukey test showed that Level 1 impact velocity $(M=3.95$, $\mathrm{SD}=0.67)$, Level 2 impact velocity $(M=7.77, S D=1.43)$, 
Table 5 The complete orthogonal array (OA)

\begin{tabular}{|c|c|c|c|c|c|c|c|c|}
\hline \multirow[t]{2}{*}{ RUN } & \multicolumn{2}{|c|}{$\begin{array}{l}\text { Inner control } \\
\text { factors array }\end{array}$} & \multicolumn{3}{|c|}{ Outer noise factor array } & \multirow{2}{*}{$\begin{array}{l}\text { Average } \\
\text { response } \\
\text { Mean }\end{array}$} & \multirow{2}{*}{$\begin{array}{l}\text { Standard } \\
\text { deviation } \\
\text { SD }\end{array}$} & \multirow{2}{*}{$\begin{array}{l}\text { Signal-to- } \\
\text { noise ratio } \\
\text { S/N }\end{array}$} \\
\hline & A & B & $\mathrm{X} 1$ & $\mathrm{X} 2$ & $\mathrm{X} 3$ & & & \\
\hline 1 & 1 & 1 & 3.75 & 5.74 & 6.58 & 5.36 & 1.45 & -14.79 \\
\hline 2 & 1 & 2 & 3.25 & 7.28 & 9.24 & 6.59 & 3.05 & -16.96 \\
\hline 3 & 1 & 3 & 2.72 & 5.81 & 7.18 & 5.24 & 2.28 & -14.90 \\
\hline 4 & 2 & 1 & 4.18 & 7.56 & 8.96 & 6.90 & 2.46 & -17.13 \\
\hline 5 & 2 & 2 & 4.20 & 9.04 & 10.96 & 8.07 & 3.48 & -18.64 \\
\hline 6 & 2 & 3 & 3.72 & 7.04 & 9.04 & 6.60 & 2.69 & -16.85 \\
\hline 7 & 3 & 1 & 4.93 & 9.14 & 10.94 & 8.34 & 3.08 & -18.80 \\
\hline 8 & 3 & 2 & 4.42 & 9.50 & 13.03 & 8.98 & 4.33 & -19.69 \\
\hline 9 & 3 & 3 & 4.41 & 8.84 & 11.40 & 8.22 & 3.54 & -18.80 \\
\hline
\end{tabular}

Table 6 Summary of the three-way ANOVA test on the inverse of the response for the three factors

\begin{tabular}{lrllrl}
\hline Source & $\mathrm{df}$ & Sum of squares & Mean square & F-Value & $p$ Value \\
\hline $\mathrm{A}$ & 2 & 0.02 & 0.01 & 46.97 & 0.00 \\
$\mathrm{~B}$ & 2 & 0.00 & 0.00 & 7.03 & 0.02 \\
$\mathrm{X}$ & 2 & 0.12 & 0.06 & 289.24 & 0.00 \\
$\mathrm{~A}^{*} \mathrm{~B}$ & 4 & 0.00 & 0.00 & 1.22 & 0.374 \\
$\mathrm{~A}^{*} \mathrm{X}$ & 4 & 0.00 & 0.00 & 2.70 & 0.11 \\
$\mathrm{~B}^{*} \mathrm{X}$ & 4 & 0.00 & 0.00 & 3.91 & 0.05 \\
Error & 8 & 0.00 & 0.00 & & \\
Total & 26 & 0.15 & & & \\
\hline
\end{tabular}

and Level 3 impact velocity $(M=9.70, S D=2.07)$ were statistically different at $p<0.05$.

\subsubsection{Interactions}

There was no significant interaction between the mass and the shape (i.e. $A$ and $B$ ) on the response $(F(4,8)=1.22$, $p=0.37)$ at $p<0.05$. There was no significant interaction between the mass and the impact velocity (i.e. $A$ and $X$ ) on the response $(\mathrm{F}(4,8)=2.70$, at $p=0.11)$ at $p<0.05$. There was no significant interaction between the shape and the impact velocity (i.e. $B$ and $X)$ on the response $(F(4,8)=3.91$, at $p=0.05)$ at $p<0.05$.

\section{Discussion}

The responses of the 27 experiments conducted suggest that the control factors and noise factor have influenced the response. The velocity and mass of impactors have been reported to affect the magnitude of the peak linear head acceleration $[24,30]$. The average responses and the results of the ANOVA test were in accordance with these findings (Tables 3 and 6). As for the shape factor, it appears to affect the response the least (Table 3). The average response for the cylinder shape was higher compared to the other shapes.

\subsection{Optimization}

The goal of Taguchi design in this study was to optimize the control factors in order to reduce the head linear acceleration. The optimization was accomplished by inspecting the average response and the corresponding average $\mathrm{S} / \mathrm{N}$ ratio at every level of the control factors (Tables 3 and 4; Fig. 5). The optimization case in this study is to produce the lowest response and highest $\mathrm{S} / \mathrm{N}$ ratio, hence, the focus is on the factor conditions that satisfy this criterion.

The optimal conditions for the mass and shape were found (Fig. 5). The mass of $0.3 \mathrm{~kg}$ achieved the lowest response. As for control factor of the shape, cube (i.e. Level 1) and wedge (i.e. Level 3 ) scored comparably the best. For the noise factor, Level 1 (i.e. $1.14 \pm 0.10 \mathrm{~m} / \mathrm{s}$ ) achieved the lowest response.

The identified conditions were $0.3 \mathrm{~kg}$ for the mass factor and cube or wedge for the shape (i.e. A1-B1 and $A 1-B 3$, respectively). Compared to other combinations, the identified optimal conditions generated relatively lower responses, for example, the individual responses at noise Level 2 and Level 3 (i.e. X2 and X3) for runs 1 and 3 (Table 5).

\subsection{Confirmation runs}

The confirmation runs are needed to validate the optimal conditions that were obtained in the previous section. To achieve that, 18 experiments were conducted (Table 6). For each of the identified conditions in the previous section, 3 runs were performed (Table 7). The confirmation runs showed that the average response values were comparable to respective ones obtained in the complete $O A$ 
(a)

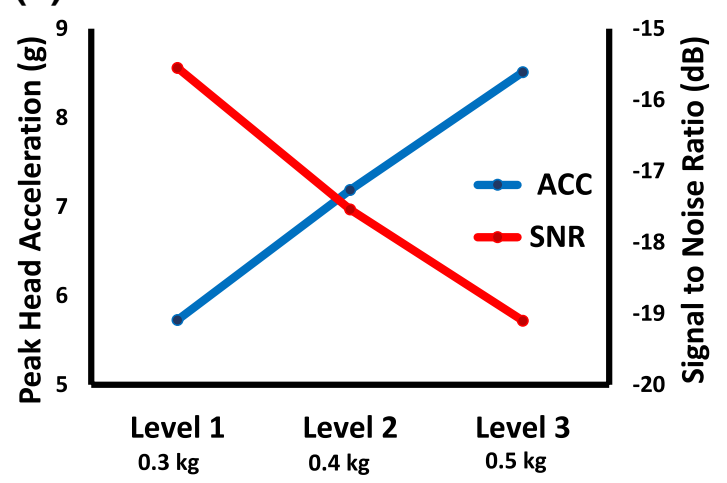

Factor A (b)

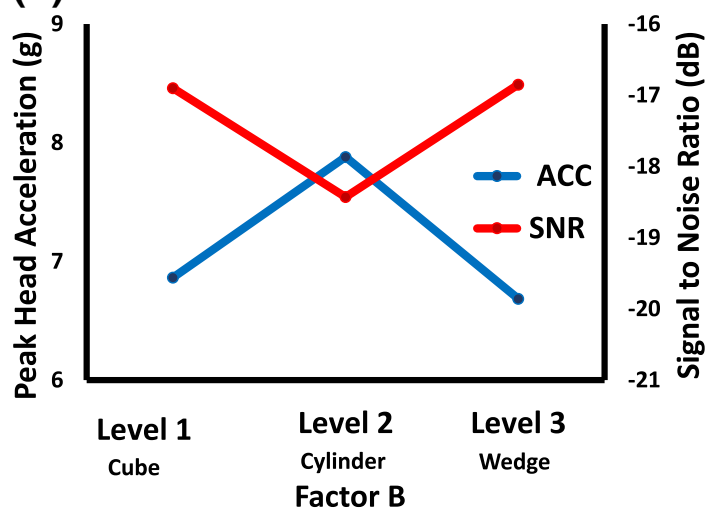

(c)

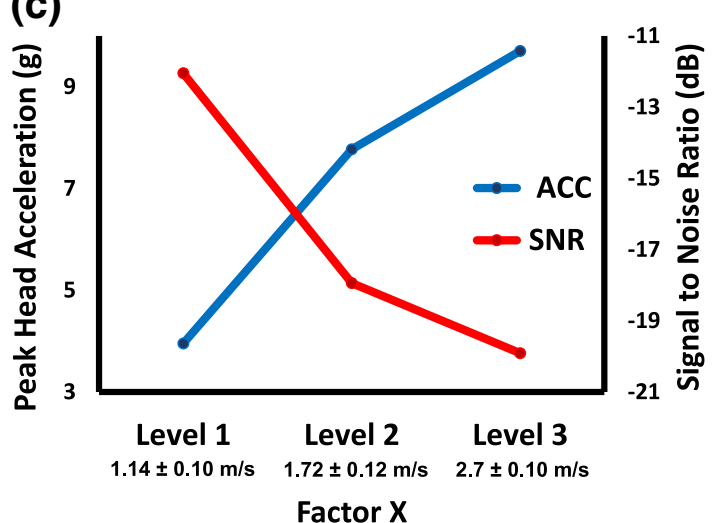

Fig. 5 The average response values and signal-to-noise $(\mathrm{S} / \mathrm{N})$ ratios for the factors investigated in this study. a For the mass. $\mathbf{b}$ For the shape. c For the impact velocity

Table 7 The responses, the average, and standard deviation for the confirmation runs. The conditions selected achieved the best responses in comparison to the other conditions in the main experiments

\begin{tabular}{llll}
\hline Combination & X1 & X2 & X3 \\
\hline A1-B1 & 3.32 & 5.48 & 7.57 \\
& 3.78 & 5.64 & 6.51 \\
& 4.04 & 6.17 & 6.46 \\
Mean (SD) & $3.71(0.36)$ & $5.76(0.36)$ & $6.85(0.63)$ \\
A1-B3 & 2.57 & 5.31 & 7.97 \\
& 2.68 & 5.28 & 6.63 \\
Mean (SD) & 3.25 & 6.18 & 7.76 \\
\hline
\end{tabular}

(Table 5), hence, confirming the optimal identified conditions for the control factors.

\subsection{Limitations of the study}

The investigation conducted in this study was limited to three factors conducted in a laboratory developed experimental setup with controlled conditions that might differ from an actual and more dynamic scenario (e.g. potential for secondary impacts). The values of the object's mass that were tested were limited to the range of $0.3-0.5$ $\mathrm{kg}$. In reality, lighter or heavier robotic toys could exist. Studying the effect of shape was limited to three basic featureless shapes. However, actual robotic forms could have other unusual shapes with a lot of detailed features. Due to the way the experimental setup was designed, the impact area for each shape was limited to achieve consistency between the experiments. The effects of different impact areas and their interactions with different shapes and surface's features were not investigated in the current work. The noise levels that were tested were limited to low velocity impacts. Hence, the generated head's accelerations from our experiments were limited to a small range (i.e. $<10 \mathrm{~g}$ ), which is unlikely to cause any potential harm. However, the toy robot could be subjected to higher velocities in an actual scenario. Finally, the investigated severity index was limited to the head acceleration. Other severity indices (e.g. tissue injuries) could be considered to investigate different effects due to different design parameters. 


\section{Conclusion}

During meltdowns, a child interacting with a social robotic toy could involuntary throw the robot to others and cause harm. In this study, the Taguchi parameter design method was used to identify the optimal design parameters for small form factor robotic toy in order to reduce the peak linear head acceleration due to impacts on the head. The investigated control factors were the mass and the shape. The impact velocity was the noise factor. Based on $L_{9}\left(3^{2}\right)$ orthogonal array, a total number of 27 experiments were conducted covering the possible combinations of the control factors and the noise factor. The optimal levels of the shape and mass that minimize the peak head linear acceleration were found based on the $\mathrm{S} / \mathrm{N}$ ratio. The three-way ANOVA test revealed statistical significance for the control factors and the noise factor in influencing the head's acceleration. The optimal levels for the control factors were as $0.3 \mathrm{~kg}$ for the mass and cube or wedge for the shape. The confirmation runs at the optimal conditions for the control factors provided the best responses as compared to other conditions.

For a given impact velocity, reducing the mass of an object appears to reduce the head acceleration considerably. This was more evident at higher impact velocities. This finding combined with our earlier findings of the application of soft materials could provide a better overall reduction in the potential harm [7]. Therefore, the designers of small social robots or robotic toys for special needs children, or even for neurotypical children, should try to minimize the mass of their products as much as possible while adding a layer of a suitable soft material. In addition to the optimization efforts at the design level, the manufacturers should include special warning labels for their products that are meant to be used by special needs users, especially those that exhibit challenging behaviors.

Optimization of a robot's design can benefit from the techniques provided by Taguchi methods as it gives an efficient and convenient way to assess and optimize the safe design of small social robots. Moreover, such benefits are magnified for two reasons. On one hand, the safety requirements of the target users, such as children with special needs who may have a tendency for meltdowns, are addressed. On the other hand, the manufacturers have done their due diligence in optimizing their design for minimizing the chances of harm to the users and avoid lawsuits or product recall later on.

Acknowledgements Open Access funding provided by the Qatar National Library. The work is supported by a research grant from Qatar University under the Grant No. QUST-1-CENG-2019-10. The statements made herein are solely the responsibility of the authors.

\section{Compliance with ethical standards}

Conflict of interest The authors declare that they have no conflict of interest.

Open Access This article is distributed under the terms of the Creative Commons Attribution 4.0 International License (http://creativeco mmons.org/licenses/by/4.0/), which permits unrestricted use, distribution, and reproduction in any medium, provided you give appropriate credit to the original author(s) and the source, provide a link to the Creative Commons license, and indicate if changes were made.

\section{References}

1. Alhaddad AY, AlKhatib SE, Khan RA, Ismail SM, Shehadeh ASS, Sadeq AM, Cabibihan JJ (2017) Toward 3D printed prosthetic hands that can satisfy psychosocial needs: grasping force comparisons between a prosthetic hand and human hands. In: Kheddar A, Yoshida E, Ge SS, Suzuki K, Cabibihan JJ, Eyssel F, He $\mathrm{H}$ (eds) Social robotics. Springer, Cham, pp 304-313

2. Alhaddad AY, Cabibihan JJ, Bonarini A (2018) Head impact severity measures for small social robots thrown during meltdown in autism. Int J Soc Robot 11:255. https://doi.org/10.1007/s1236 9-018-0494-3

3. Alhaddad AY, Cabibihan J-J, Hayek A, Bonarini A (2018) The impact of different shaped objects of different masses at different impact velocities on a dummy head (dataset). Version VI. Harvard Dataverse. https://doi.org/10.7910/DVN/AVC8GG

4. Alhaddad AY, Cabibihan JJ, Hayek A, Bonarini A (2019) Data on the impact of an object with different thicknesses of different soft materials at different impact velocities on a dummy head. Data Brief 24:103885. https://doi.org/10.1016/j.dib.2019.103885

5. Alhaddad AY, Cabibihan JJ, Hayek A, Bonarini A (2019) Data on the impact of objects with different shapes, masses, and impact velocities on a dummy head. Data Brief 22:344-348. https://doi. org/10.1016/j.dib.2018.11.143

6. Alhaddad AY, Cabibihan JJ, Hayek A, Bonarini A (2019) A low-cost test rig for impact experiments on a dummy head. HardwareX e00068

7. Alhaddad AY, Cabibihan JJ, Hayek A, Bonarini A (2019) Safety experiments for small robots investigating the potential of soft materials in mitigating the harm to the head due to impacts. SN Appl Sci 1(5):476. https://doi.org/10.1007/s42452-019-0467-7

8. Alhaddad AY, Javed H, Connor O, Banire B, AI Thani D, Cabibihan $J J(2018)$ Robotic trains as an educational and therapeutic tool for autism spectrum disorder intervention. In: International conference on robotics and education RiE 2017. Springer, pp 249-262

9. Anderson VA, Catroppa C, Dudgeon P, Morse SA, Haritou F, Rosenfeld JV (2006) Understanding predictors of functional recovery and outcome 30 months following early childhood head injury. Neuropsychology 20(1):42

10. Baghdadli A, Pascal C, Grisi S, Aussilloux C (2003) Risk factors for self-injurious behaviours among 222 young children with autistic disorders. J Intellect Disabil Res 47(8):622-627

11. Bodfish JW, Symons FJ, Parker DE, Lewis MH (2000) Varieties of repetitive behavior in autism: comparisons to mental retardation. J Autism Dev Disord 30(3):237-243

12. Brown D Tracker 5.0.7. https://physlets.org/tracker/. Accessed 22 Mar 2019

13. Cabibihan J, Javed H, Sadasivuni K, Al Haddad A (2018) Smart robotic therapeutic learning toy. WIPO Patent WO2018033857, World Intellectual Property Organization 
14. Cabibihan JJ, Chellali R, So CWC, Aldosari M, Connor O, Alhaddad AY, Javed H (2018) Social robots and wearable sensors for mitigating meltdowns in autism - a pilot test. In: International conference on social robotics. Springer, pp 103-114. https:// doi.org/10.1007/978-3-030-05204-1_11

15. Cabibihan JJ, Javed H, Ang M Jr, Aljunied SM (2013) Why robots? A survey on the roles and benefits of social robots in the therapy of children with autism. Int J Soc Robot 5(4):593-618

16. Cabibihan Jj, Javed H, Sadasivuni KK, Alhaddad AY (2019) Smart robotic therapeutic learning toy. US Patent App. 16/326,169

17. Cabibihan JJ, Sadasivuni KK, Alhaddad AY (2019) Biometric liveness detection through biocompatible capacitive sensor US Patent App. 16/058,453

18. Cabibihan JJ, So WC, Nazar M, Ge SS (2009) Pointing gestures for a robot mediated communication interface. In: International conference on intelligent robotics and applications. Springer, Berlin, pp 67-77

19. Cabibihan JJ, So WC, Saj S, Zhang Z (2012) Telerobotic pointing gestures shape human spatial cognition. Int J Soc Robot 4(3):263-272

20. Cavazzuti M (2012) Optimization methods: From theory to design scientific and technological aspects in mechanics. Springer, Berlin

21. Diehl JJ, Schmitt LM, Villano M, Crowell CR (2012) The clinical use of robots for individuals with autism spectrum disorders: a critical review. Res Autism Spect Disord 6(1):249-262

22. Diep L, Cabibihan JJ, Wolbring G (2014) Social robotics through an anticipatory governance lens. International conference on social robotics. Springer, Cham, pp 115-124

23. Emanuelson I (2003) How safe are childcare products, toys and playground equipment? A swedish analysis of mild brain injuries at home and during leisure time 1998-1999. Inj Control Saf Promot 10(3):139-144

24. Haddadin S, Albu-Schaffer A, Hirzinger G (2008) The role of the robot mass and velocity in physical human-robot interactionPart I: non-constrained blunt impacts. In: IEEE international conference on robotics and automation, 2008. ICRA 2008. IEEE, pp 1331-1338

25. Ham J, van Esch M, Limpens Y, de Pee J, Cabibihan JJ, Ge SS (2012) The automaticity of social behavior towards robots: the influence of cognitive load on interpersonal distance to approachable versus less approachable robots. In: International conference on social robotics. Springer, pp 15-25

26. Hamada M (1993) Reliability improvement via taguchi's robust design. Qual Reliab Eng Int 9(1):7-13. https://doi.org/10.1002/ qre.4680090105

27. Hebbale AM, Bekal A, Srinath MS (2019) Wear studies of composite microwave clad on martensitic stainless steel. SN Appl Sci 1(3):196. https://doi.org/10.1007/s42452-019-0214-0

28. Herrmann G, Melhuish C (2010) Towards safety in human robot interaction. Int J Soc Robot 2(3):217-219

29. Hoa TD, Cabibihan JJ (2012) Cute and soft: baby steps in designing robots for children with autism. In: Proceedings of the workshop at SIGGRAPH Asia. ACM, pp 77-79

30. Hutchinson TP (2014) Peak acceleration during impact with helmet materials: effects of impactor mass and speed. Eur J Sport Sci 14(sup1):S377-S382

31. Kanne SM, Mazurek MO (2011) Aggression in children and adolescents with asd: prevalence and risk factors. J Autism Dev Disord 41(7):926-937

32. Matson JL, Gonzalez ML, Rivet TT (2008) Reliability of the autism spectrum disorder-behavior problems for children (ASD-BPC). Res Autism Spect Disord 2(4):696-706

33. Mihalik JP, Blackburn JT, Greenwald RM, Cantu RC, Marshall SW, Guskiewicz KM (2010) Collision type and player anticipation affect head impact severity among youth ice hockey players. Pediatrics 125(6):e1394-e1401

34. Moayyedian M, Derakhshandeh JF, Said S (2018) Experimental investigations of significant parameters of strain measurement employing taguchi method. SN Appl Sci 1(1):92. https://doi. org/10.1007/s42452-018-0075-y

35. Montgomery DC (2017) Design and analysis of experiments. Wiley, Hoboken

36. Mori T (2011) Taguchi methods: benefits, impacts, mathematics, statistics, and applications. ASME Press, New York

37. Moss WC, King MJ, Blackman EG (2014) Towards reducing impact-induced brain injury: lessons from a computational study of army and football helmet pads. Comput Methods Biomech Biomed Eng 17(11):1173-1184

38. O'Sullivan DM, Fife GP, Pieter W, Shin I (2013) Safety performance evaluation of taekwondo headgear. Br J Sports Med 47(7):447-451

39. Rivara FP, Koepsell TD, Wang J, Temkin N, Dorsch A, Vavilala MS, Durbin D, Jaffe KM (2012) Incidence of disability among children 12 months after traumatic brain injury. Am J Public Health 102(11):2074-2079

40. Rowson S, Duma SM (2011) Development of the star evaluation system for football helmets: Integrating player head impact exposure and risk of concussion. Ann Biomed Eng 39(8):2130-2140

41. Rowson S, Duma SM (2013) Brain injury prediction: assessing the combined probability of concussion using linear and rotational head acceleration. Ann Biomed Eng 41(5):873-882

42. Sadasivuni K, Al Haddad A, Javed H, Yoon W, Cabibihan JJ (2017) Strain, pressure, temperature, proximity, and tactile sensors from biopolymer composites. In: Sadasivuni KK, Cabibihan JJ, Ponnamma D, Al-Maadeed MA, Kim J (eds) Biopolymer composites in electronics. Elsevier, Amsterdam, pp 437-457

43. So WC, Wong MY, Cabibihan JJ, Lam CY, Chan RY, Qian HH (2016) Using robot animation to promote gestural skills in children with autism spectrum disorders. J Comput Assist Learn 32(6):632-646

44. Solutions, humanetics innovative: Hybrid III 3 year old child. Child Dummies, URL: http://www.humaneticsatd.com/crashtest-dummies/children/hiii-3yo (2017). Accessed 1 Jan 2018

45. Taguchi G, Wu Y (1979) Introduction to off-line quality control. Central Japan Quality Control Association, Nagoya, Japan

46. Tamizharasan T, Senthilkumar N, Selvakumar V, Dinesh S (2019) Taguchi's methodology of optimizing turning parameters over chip thickness ratio in machining $\mathrm{p} / \mathrm{m}$ AMMC. SN Appl Sci 1(2):160. https://doi.org/10.1007/s42452-019-0170-8

47. Taylor CA (2017) Traumatic brain injury-related emergency department visits, hospitalizations, and deaths-United States, 2007 and 2013 MMWR. Surveill Summ 66:1

48. Teo HT, Cabibihan JJ (2015) Toward soft, robust robots for children with autism spectrum disorder. In: FinE-R@ IROS, pp 15-19

49. Wykowska A, Kajopoulos J, Obando-Leiton M, Chauhan SS, Cabibihan JJ, Cheng G (2015) Humans are well tuned to detecting agents among non-agents: examining the sensitivity of human perception to behavioral characteristics of intentional systems. Int J Soc Robot 7(5):767-781

50. Yang NH, Rodowicz KA, Dainty D (2014) Baseball Head Impacts to the Non-Helmeted and Helmeted Hydrid III ATD. In: ASME 2014 international mechanical engineering congress and exposition, vol 3. Biomedical and Biotechnology Engineering, p V003T03A007

51. Young TJ, Daniel RW, Rowson S, Duma SM (2014) Head impact exposure in youth football: elementary school ages 7-8 years and the effect of returning players. Clin J Sport Med 24(5):416-421

Publisher's Note Springer Nature remains neutral with regard to jurisdictional claims in published maps and institutional affiliations. 